\title{
Developing the Learning Outcomes of the Students through Microscale Experiments in Chemistry
}

\author{
Agnes R. Pesimo \\ Partido State University, Goa, Philippines \\ Email: agnespesimo@yahoo.com
}

Received 5 April 2014; revised 15 May 2014; accepted 24 June 2014

Copyright (C) 2014 by author and OALib.

This work is licensed under the Creative Commons Attribution International License (CC BY). http://creativecommons.org/licenses/by/4.0/

(c) (i) Open Access

\section{Abstract}

The study was conducted to evaluate the effectiveness of the designed microscale experiments in developing the learning outcomes of the students along the cognitive, affective and psychomotor domains. It was meant to describe and compare the learning outcomes of the students who were exposed and not exposed to microscale experiments and identified the learning experiences of the students exposed to the microscale experiments. The study used the pretest and posttest randomized control group design and subjected the experimental group to the microscale experiments and the control group to the traditional method of performing chemistry experiments. The results of the study showed that the designed microscale experiments were effective in developing the learning outcomes of the students in Chemistry. It was able to improve the learning competencies of the students in the cognitive, affective and psychomotor domain. The positive learning experiences of the students in performing microscale experiments in Chemistry accounts for the development of the students' learning outcomes.

\section{Keywords}

Developing, Learning Outcomes, Experiments in Microscale Chemistry

Subject Areas: Inorganic Chemistry

\section{Introduction}

A new trend in teaching Chemistry is the use of experiments in the microscale level. This innovative teaching strategy does not just save time and effort but solve problems and issues on the high cost of chemicals and apparatuses. According to the Microscale Chemistry Center [1], working microscale techniques in chemistry can decrease the quantity of wastes dumped into the ecosystem, the toxicity and hazards to students and teachers, the 
cost of reagents and energy, the breakage of glass materials and the quantity of products and reagents wasted. In many parts of the world, higher educational institutions are now shifting their experiments to the microscale level. Schools like the University of Michigan, Department of Chemistry began implementing microscale chemistry techniques in the undergraduate teaching laboratories [2]. Microscale laboratory experiments reduce the amount of chemicals necessary to perform undergraduate chemistry experiments to a fraction of what was historically used. In addition to decreasing the quantities of chemicals purchased and amount of chemical waste generated, microscale techniques have proven to be safer and more cost effective than traditional experiments. Bemidji State University was able to decrease lab waste by nearly 35 percent and reduced reagent use by 33 liters per year. The department estimates $\$ 1800$ in annual savings from purchasing/less reagent and reduced disposal cost. By reducing inventory, it also has recovered storage space, allowing for better organization. Changes included scaling down additional experiments to small and microscale, distillation and reuse, and eliminating or finding alternative experiments. Over 90 percent of the savings from the intern project resulted from micro scaling experiments [3].

Microscale experiments in the Philippines are not fully developed and many higher institutions are still using the macro scale or the traditional methods of conducting experiments in Chemistry. It is good to note that there are already some activities like seminars, conferences and conventions that promote microscale chemistry in the country. Some higher education institutions in the country are already developing experiments on the microscale level such as the study conducted by Boongaling and Hernandez who downscaled the synthesis of 2,4-dinitrophenylhydrazine from 1-chloro-2,4-dinitrobenzene and Hydrazine [4]. Binas, et al., developed a low cost clear box microscale digital polarimeter [5], Albano, D.R and Sevilla, F. III. developed a low cost electronic thermometer for microscale thermometry [6]. Cabral, et al. validated the downscaled analyses of acid and ester values of essential oils [7]. None of these studies have conducted an evaluation on the learning outcomes when using microscale experiments. Most are laboratory processes and materials developments. None from among the HEIs in the country adopted the microscale experiments in the undergraduate education.

Student learning outcomes are defined in terms of the knowledge, skills, and abilities that students have attained as a result of their involvement in a particular set of educational experiences. It can increase the level of awareness and involvement in their own learning. It is an approach to curriculum assessment and change, a context for course design and revision and an important step towards clear communication of expectations to students [8]. Learning outcomes are concerned with the achievements of the learner rather than the intentions of the teacher (expressed in the aims of a module or course). They can take many forms and can be broad or narrow in nature [9].

Learning outcomes can be measured directly and indirectly. Indirect measures include data from surveys of seniors and alumni, retention rates, graduation rates, number of students progressing to advanced degrees, etc. They allow administrators, faculty, researchers, and consumers to infer the benefits to students from their years in college, but they cannot report with precision exactly what students have learned or what they are capable of doing as a result of their university education. Historically, these kinds of data have been collected by offices of institutional research, alumni offices, etc. Direct measures provide more evidence of the increase in students' knowledge and abilities over a period of time. Standardized test is one kind of direct measure [10]. The findings of the study of Gravoso, et al. suggest that technology can change and improve the quality of learning outcomes if designed to support knowledge construction in a learner-centered learning environment [11].

The microscale approach in performing experiments in Chemistry can be adopted by educational institutions in both the tertiary and secondary level as a solution to the unavailability of chemicals and apparatus because they are expensive and many educational institutions could hardly afford. In using the microscale experiments, the performance of the students may be affected because it uses downscaled materials and could affect students' learning capabilities and these needs to be evaluated.

The effectiveness of the designed microscale experiments developed in this study was evaluated in terms of the learning outcomes manifested by the students along the cognitive, affective, and psychomotor domains as they performed each of the designed microscale experiments. The designed microscale experiment is effective if the students who used the experiments have the same or better learning outcomes compared to those who used the traditional methods of performing chemistry experiments.

Through this study, the different learning experiences of the students who used the microscale experiments will be identified and determine how these learning experiences affected their learning behaviors and outlook in life. This would also show the functionality of the designed experiments towards the attainment of the different 
levels of learning competencies expected from them in chemistry education.

\section{Objectives}

The main purpose of the study is to evaluate the effectiveness of the designed microscale experiments in developing the learning outcomes of the students along the cognitive, affective and psychomotor domains of the students. Specifically, the study was conducted to:

1) Describe the learning outcomes of the students who used and did not use microscale experiments along the cognitive, affective and psychomotor development.

2) Compare the learning outcomes of the students who were exposed and not exposed to microscale experiments.

3) Identify the learning experiences of the students who performed the microscale experiments and their effects towards the development of the students learning outcomes.

\section{Significance of the Study}

The use of microscale experiments in Chemistry is an innovation in the teaching-learning process. It can reduce the cost of laboratory supplies and materials and minimize chemical wastage without affecting the learning outcomes of the students. Exploratory approach in the teaching of chemistry which can lead to the students' high level thinking and manipulative skills is encouraged. Students are given more chance to conduct the experiment in a 1:1 ratio or in smaller group activities. With this, students develop a greater appreciation of the chemistry concepts and principles because learning is based on experiences and observations.

The microscale experiments can accelerate the level performance of the students and this lead to full satisfaction and fulfillment of instructors and professors teaching chemistry. Because of this, they are more motivated to provide instruction to the students and makes them more effective and efficient.

The microscale experiments can help solve problems on high cost of chemicals and supplies and the chemistry instructors' need for instructional materials can be readily provided. With a meager budget, the administration can purchase more supplies and materials for chemistry experiments and allows more students to venture on various laboratory activities at a more affordable cost. Since more students are given the opportunity to conduct experiments, learning is more fun and interesting. Enjoyment in teaching enhances academic performance, an indicator of quality and excellence.

\section{Conceptual Framework}

The three concepts that were interrelated to each other are the Chemistry Students, the Microscale experiments and the Learning outcomes or the students (Figure 1). Two groups of Chemistry students (A), the experimental and control group were exposed to 12 Chemistry experiments (B) with the experimental group using the microscale experiments and the control group using the macroscale or the traditional method of performing experiments. The two groups were exposed to different learning experiences which can be measured in terms of their cognitive, affective and psychomotor domains (C). The performance of the students in the three domains were compared to the students who were not exposed to the 12 microscale experiments to determine the effectiveness of the designed microscale experiments in developing the learning outcomes of the students. Ones found effective, the designed microscale experiments can be used as an instructional material and as an innovation in Chemistry Education.

\section{Methodology}

The study used the pretest and posttest randomized control group design. In this design, the students were grouped into experimental and control group through randomization and lottery. Randomization was based on the results of their PSU Entrance test, a standardized test used to evaluate the student's aptitude, after the selection of the experimental and control groups, the pretest was administered to them using the 50-item summative test and the same instrument was used during the posttest. The summative pre and post test evaluation were conducted before and after the conduct of the 12 experiments and the formative pre and post test evaluation were administered before and after each experiment (Figure 2).

The summative test has undergone several processes which include the preparation of the table of specifica- 


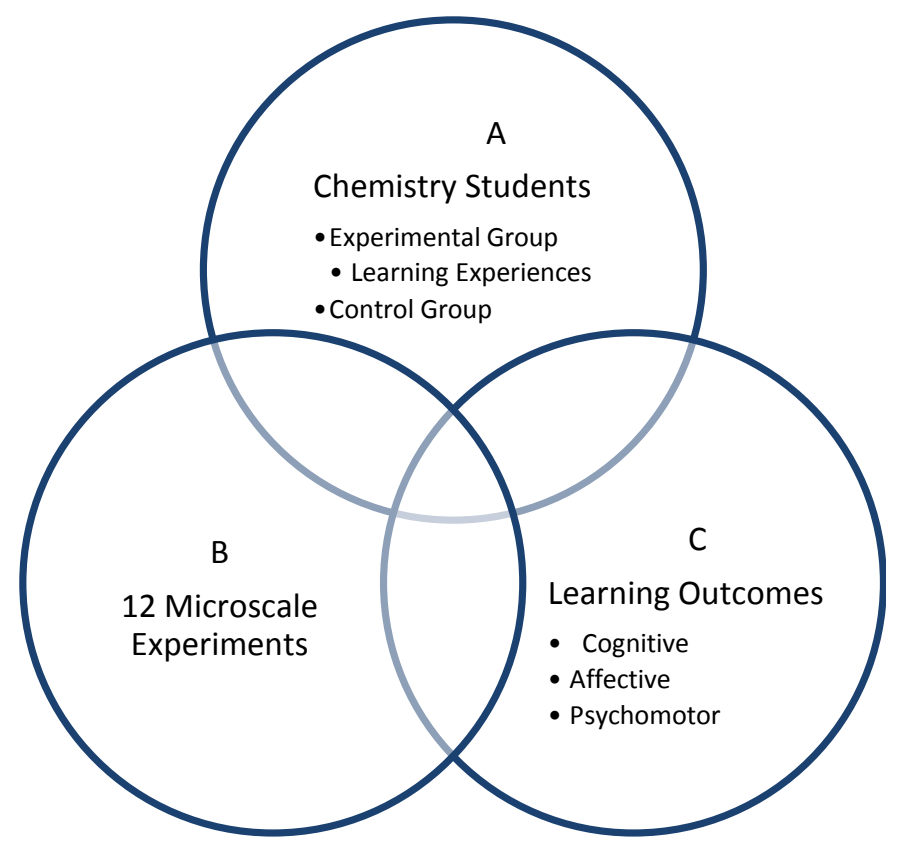

Figure 1. The diagram shows how the microscale experiments could affect the learning outcomes of the students through their cognitive, affective and psychomotor domains. The effectiveness of the 12 experiments can be measured by comparing the performances of the microscale groups with the control groups.



Figure 2. The diagram shows experimental study to two groups of randomly selected students. Pretest was administered to both groups and treatment was undertaken to the experimental group by using the microscale experiments. The performance of the two groups was compared through the posttest administered after the treatment.

tions, the construction of the tests, dry run, item analysis, revision and final drafting. The item analysis of the test showed that the level of difficulty of the test are $9 \%$ easy, $16 \%$ moderate, $31 \%$ difficult and $44 \%$ very difficult and the index of discrimination is $25 \%$ and very good, $16 \%$ moderate, $12 \%$ fair and $32 \%$ poor. Items that were very difficult, easy and poor index of discrimination were either revised or discarded. The test items were also statistically treated with the Pearson product correlation to find out that the summative test is highly reliable (0.86) and highly valid (0.93). The 10-item formative test used to evaluate students' performance every end of the experiment was also used to evaluate student's level of cognition per experiment. The test items were basically focused on the topics performed in the experiment and its reliability $(0.78)$ and validity $(0.80)$ were made by correlating the result of the test before and after performing each experiment. With respect to the evaluation of the students' psychomotor and affected skills, rubrics were developed based on Bloom's Taxonomy of Objectives for psychomotor and affective development.

The microscale experiments used in this study were carefully designed by the researcher reducing mostly the amount by $10 \%$ of its original quantity. It also used indigenous materials for some apparatus like the syringe instead of graduated cylinder, vials for test tubes, and $10 \mathrm{ml}$ bottles for liquid containers. Some equipment and apparatus that were not modified in this experiment are the thermometer, weighing scales, $\mathrm{pH}$ papers, stopwatch 
and multimeter. These were not modified especially if the experiment requires accuracy of measurement.

After the pretest, the experimental group was exposed to microscale experiments and they were made to perform 12 microscale experiments using downscaled materials by $1 / 10^{\text {th }}$ of the original materials. Following gives a brief description of the 12 experiments used.

Experiment No. 1: Measuring the density of liquids and solids. The first experiment (conducted by the students were focused on the development of the student's measuring skills using the syringe as measuring tool for the volume of liquids and irregularly shaped solids.

Experiment No. 2: Identifying household substances the second experiment, was intended to develop the student's skills and understanding in identifying household substances based on their chemical and physical properties. In this experiment, they were given common household substances like vinegar, salt, sugar, and many others and distinguish each substance based on chemical and physical characteristics.

Experiment No. 3: Classifying Household Substances. The third experiment (Classifying chemical substances) dealt on the classification of substances according to appearance, composition, homogeneity and separation techniques. It is basically about the study of matter as pure or mixture of substances. It used small amount of substances ( $1 \mathrm{~g}$ for solid and $1 \mathrm{ml}$ for liquid).

Experiment No. 4: Constructing Molecular Models The fourth experiment (constructing molecular models), was aimed to visualize the concept of an atom and moelcules, how they were arranged using the principle of VSEPR Theory. It used materials like modeling clays to represent molecules or atoms and toothpicks as chemical bonds. Sizes of atomic models are limited to $1-5 \mathrm{~cm}$ in length of stick.

Experiment No. 5: Classifying Acids and Bases the fifth experiment (pH measurements and their properties) was conducted by the students and the main purpose of it is for the students to distinguish an acid from a base and measure the degree of its alkalinity and basicity. The $\mathrm{pH}$ paper was still used in this experiment but other materials like vinegar, soup solution, shampoo, etc., replaced the chemicals like hydrochloric acid, sodium hydroxide and other chemicals.

Experiment No. 6: Preparing and Separating Solutions. The students in this experiment were made to prepare solutions in percentage and molarity using salt and water and later were asked to separate them using the evaporation process. It used improvised materials like alcohol stove and aluminum cans as evaporator. The mass of the solute was measured using the weighing balance with accuracy of 0.01 and the syringe was used to measure the volume of water.

Experiment No. 7: Identifying chemical reactions. This experiment dealt with the different kinds of chemical reactions. It used the learning approach to accommodate more experiment in a limited supplies and apparatus. It used locally available materials such as sugar, eggshells, vinegar or muriatic acid, micro vials, bottle caps, and an improvised micro vial holders and microalcohol stoves.

Experiment No. 8: Rates of chemical reactions. The purpose of this activity is to develop the student's awareness on the different factors that affect the chemical reactions. It used the learning station to develop the concept. Each learning station corresponds to one factor for the students to discover.

Experiment No. 9: Stoichiometry of a chemical reaction. This experiment was focused on the stoichiometry of chemical reaction and was aimed to develop the student's skills in calculating the actual yield in a chemical reaction in an actual experimental setting. Vials were used as reaction site, syringe was used to measure and dispense liquids. Micro funnel was used as filter.

Experiment No. 10: Properties and preparation of gases. The main concern of the experiment was to develop the students' skills on generating gases using available materials and set ups in a downscaled experimental set ups. A $50 \mathrm{ml}$ vial was used as the reaction site and a $10 \mathrm{ml}$ vial was used as the receiver. The dextrose hose was connected directly from the reaction to receiving vessel. The chemical characteristics of the gas were observed by injecting the reagent into the vials containing the collected samples of gases.

Experiment No. 11: Enthalpy and entropy of a chemical reaction. The topic is more on thermodynamics to give the students concepts that chemical reactions undergo changes in heat. It used calcium carbonate, calcium oxide hydrochloric acid and water. The amount used is for solid substances is $1 \mathrm{~g}$ instead of $10 \mathrm{~g}$ and for liquids $1 \mathrm{ml}$ instead of $10 \mathrm{ml}$. Syringe was used to measure the volume. Weighing scale at 0.01 accuracy were used to get the mass of the substance and thermometer with 0.1 calibration was used to measure mass and temperature respectively.

Experiment No. 12: Electrochemical cells. Basic knowledge about the electrochemistry of some common substances were developed among students through the use of an electrochemical set. Materials used for the set 
up are vials as the reaction site, strips of metals like aluminum, copper and tin were used as electrodes and the multimeter with accuracy of 0.01 was used to measure the amount of current generated per chemical reaction. This is an exploratory activity that allows the students to discover the difference between the galvanic and electrochemical cells in the set up they prepared.

The macroscale experiments used the amount of materials and apparatuses prescribed in common Chemistry Laboratory manuals of Lemay [12], Slowinski [13], Beran [14], Silberberg [15] Rodriguez and de Mesa [16].

The learning outcomes of the students were determined using the 10-item formative tests given before and after the conduct of each experiment for the cognitive domains and rubrics for the affective and psychomotor domains. The rubrics for the affective domains included the 5 expected behavioral skills which are the receiving, responding, valuing, organizing and internalizing. The rubrics for the psychomotor skills are composed of expected perception, set, guided response, mechanism and complex overt responses. Results of the evaluation were categorized into outstanding, very satisfactory, satisfactory, fair and poor.

Likewise, the learning outcomes of the students in the experimental and control groups were compared using the t-test and was processed with the help of the SPSS software. Results of the statistical calculation were interpreted as highly significant, significant and not significant.

The study used an open ended questionnaire to find out the different learning experiences of the students. A set of questions were given to the students and were asked to list down their experiences while performing the experiments. These data were analyzed in terms of their contribution to the development of the different learning behaviors expected from them.

\section{Results and Discussion}

The Students' Learning Outcomes. The degree of the behavioral changes among students when performing the experiments was evaluated in the three domains of development. The cognitive development of the students was viewed in terms of their performance in the summative and formative tests. The affective and psychomotor skills of the students were evaluated through the ratings made by the students, peers and the instructors in the rubrics. Table 1 shows the learning outcomes of the students in the cognitive domain.

Cognitive Skills. The formative tests given in each experiment were very useful in determining the extent of the skills development of the students in the cognitive domain. The table below shows the performance of the students in the formative tests. The data show that the students in the experimental group has outstanding performance in Experiments numbers 2, 3, 8 and 9 and has shown very satisfactory performance in the rest of the experiments.

In the control group, the students' performance ranges from very satisfactory in experiment numbers $1,2,3$ and 9 to satisfactory in the rest of the experiments. Only in experiment No. 1 that the students in the two groups have obtained the same level of performance. In the overall performance of the students, the experimental group has very satisfactory performance and the control group only satisfactory.

The data implies that the microscale experiments were able to meet the desired learning outcomes and mastery level as shown by their very satisfactory performance in the experiments conducted. It also means that the microscale experiments are effective in developing the learning outcomes of the students in the cognitive level.

Table 1 also shows that the mean score obtained by the students in the experimental group is higher than the mean score obtained by the students in the control group. In experiments 1,3 , and 6 , the p-value is less than the 0.05 which means that the mean score of the students is significantly different. In experiments 2, 4, 8, 9, 10, 11 and 12 , the p-value is less than 0.01 indicating that there is a very high significant difference in the proficiency level of the students. This suggests that the students who used microscale experiments have better performance. It further implies that the microscale experiments were capable of improving students' performance in Chemistry. It can also be noted that the p-value in experiments 3,5 and 10 is greater than 0.05 indicating that the performance of the students is not significantly different or the students in both groups have the same level of performance which means that in the two experiments, the microscale experiments is still a good teaching innovation to improve student performance in Chemistry even if the amount of materials were reduced by $1 / 10^{\text {th }}$ its original value.

Table 1 also showed that the level of performance of the students in the summative test of both groups of students has very satisfactory performance but the difference in the performance of the two groups is statistically significant at $1 \%$ level of significance. It means that the overall performance of the students who used the 
Table 1. Students learning outcomes in the formative tests in the control and experimental groups.

\begin{tabular}{|c|c|c|c|c|c|c|}
\hline \multirow{2}{*}{ Expt No. } & \multicolumn{2}{|c|}{$\begin{array}{c}\text { Control Group } \\
\text { (Used Conventional Method) }\end{array}$} & \multicolumn{2}{|c|}{$\begin{array}{c}\text { Experimental Group } \\
\text { (Used Microscale Experiments) }\end{array}$} & \multirow{2}{*}{ t-Value } & \multirow{2}{*}{ Sigma } \\
\hline & PL & Interpretation & PL & Interpretation & & \\
\hline \multicolumn{7}{|l|}{ Formative Tests } \\
\hline 1 & 60.91 & VS & 70.45 & VS & 0.96 & $0.04^{*}$ \\
\hline 2 & 67.65 & VS & 81.18 & $\mathrm{O}$ & 1.35 & $0.01^{* *}$ \\
\hline 3 & 73.00 & VS & 82.50 & $\mathrm{O}$ & 0.95 & $0.06^{\mathrm{ns}}$ \\
\hline 4 & 50.00 & S & 64.74 & V S & 1.47 & $0.00^{* *}$ \\
\hline 5 & 53.68 & S & 63.68 & VS & 1.00 & $0.09^{\text {ns }}$ \\
\hline 6 & 56.00 & S & 66.00 & VS & 1.00 & $0.02^{*}$ \\
\hline 7 & 54.12 & S & 74.12 & VS & 2.00 & $0.00^{* *}$ \\
\hline 8 & 51.58 & S & 88.42 & $\mathrm{O}$ & 3.68 & $0.00^{* *}$ \\
\hline 9 & 67.50 & VS & 86.50 & $\mathrm{O}$ & 1.90 & $0.01^{* *}$ \\
\hline 10 & 60.50 & VS & 70.00 & VS & 0.95 & $0.11^{\text {ns }}$ \\
\hline 11 & 58.09 & S & 72.60 & VS & 1.65 & $0.00^{* *}$ \\
\hline 12 & 58.28 & S & 73.04 & VS & 1.48 & $0.00^{* *}$ \\
\hline Summative Test & 64.26 & VS & 77.13 & VS & 1.47 & $0.00^{* *}$ \\
\hline
\end{tabular}

81 - 100 Outstanding (O), 61 - 80 Very Satisfactory (VS), 41 - 60 Satisfactory (S), 21 - 40 Fair (F), 0 - 20 Poor (P); ${ }^{* *}$ Highly significant, ${ }^{*}$ Significant, ${ }^{\mathrm{ns}}$ not significant, PL: Performance Level.

microscale experiments is better than those who used the conventional or macroscale experiments. This indicates that using the microscale experiments can improve the students' performance in Chemistry.

Affective Skills. The affective skills development of the students was also evaluated by the study and the result of the evaluation is summarized in Table 2.

The data show that the affective skills development of the students in the experimental group varies from very satisfactory to outstanding while the students in the control group have shown satisfactory to very satisfactory performance. On the average, the students in the experimental group have obtained an outstanding affective skills development while those in the experimental group have obtained only a very satisfactory rating. This finding signifies that the students in the experimental group have acquired a much higher level of affective skills development developing the different levels of the affective domain which are receiving, responding to phenomena, valuing, organization and characterization.

Comparing the affective skills development of the students in the control and experimental group, data shows that the performance of the students in the 12 experiments who used the microscale experiments is better than those who used the usual method of performing the experiments. This is shown when the mean score of the students who used the microscale experiments is higher than those who did not and the p-value is less than 0.001 in 12 experiments. The data implies that the affective skills of the students who used the microscale experiments is significantly different than those who did not use microscale experiments and this means that the former group of students has obtained better affective skills development.

Psychomotor Skills. The psychomotor skills developed among the students were evaluated and the summary of it is presented in Table 3. The data revealed that the students in the experimental group have outstanding and very satisfactory ratings whereas those in the control group have only very satisfactory ratings. On the average, both the control and experimental group earned a rating of very satisfactory. This indicates that the students in the experimental group and control group have acquired the same level of psychomotor skills. This means that the manipulative skills of the students can be well developed even if the microscale experiments were used.

The foregoing findings show that the designed microscale experiments can cause positive behavioral changes in the three learning domains and enhance the learning capabilities of the students. Behavioral changes among students were observed and the expected learning outcomes for the Chemistry students were met. The students' learning outcome when microscale experiments were used is very satisfactory to outstanding and this is an indication that the students have acquired mastery and high level performance in the different learning domains. 
Table 2. Learning outcomes of the two groups of students in the affective skills.

\begin{tabular}{|c|c|c|c|c|c|c|}
\hline \multirow[t]{2}{*}{ Experiment No. } & \multicolumn{2}{|c|}{$\begin{array}{c}\text { Control Group } \\
\text { (Used Conventional Method) }\end{array}$} & \multicolumn{2}{|c|}{$\begin{array}{c}\text { Experimental Group } \\
\text { (Used Microscale Experiments) }\end{array}$} & \multirow[t]{2}{*}{ t-Value } & \multirow{2}{*}{$\begin{array}{c}\text { Sigma } \\
\text { (p-Value) }\end{array}$} \\
\hline & Mean & Interpretation & Mean & Interpretation & & \\
\hline 1 & 3.20 & VS & 4.30 & $\mathrm{O}$ & 5.47 & $0.00^{* *}$ \\
\hline 2 & 3.04 & VS & 4.09 & $\mathrm{O}$ & 4.07 & $0.00^{* *}$ \\
\hline 3 & 3.34 & VS & 4.13 & $\mathrm{O}$ & 2.92 & $0.01^{* *}$ \\
\hline 4 & 3.25 & VS & 3.88 & VS & 2.69 & $0.01^{* *}$ \\
\hline 5 & 3.22 & VS & 3.79 & VS & 2.02 & $0.06^{*}$ \\
\hline 6 & 3.22 & VS & 3.85 & VS & 2.30 & $0.03^{* *}$ \\
\hline 7 & 3.30 & VS & 4.26 & $\mathrm{O}$ & 3.45 & $0.00^{* *}$ \\
\hline 8 & 2.49 & VS & 4.15 & $\mathrm{O}$ & 6.36 & $0.00^{* *}$ \\
\hline 9 & 2.49 & VS & 3.82 & VS & 3.38 & $0.00^{* *}$ \\
\hline 11 & 3.10 & VS & 4.37 & $\mathrm{O}$ & 5.73 & $0.00^{* *}$ \\
\hline 12 & 3.09 & VS & 4.23 & $\mathrm{O}$ & 6.00 & $0.00^{* *}$ \\
\hline Average & 3.06 & VS & 4.10 & $\mathrm{O}$ & 3.78 & $0.00^{* *}$ \\
\hline
\end{tabular}

81 - 100 outstanding (O), 61 - 80 Very Satisfactory (VS), 41 - 60 Satisfactory (S), 21 - 40 Fair (F), 0 - 20 Poor (P); ${ }^{* *}$ Highly significant, *Significant, ${ }^{\mathrm{ns}}$ Not significant.

Table 3. Psychomotor skills developed among the students in the experimental and control group.

\begin{tabular}{|c|c|c|c|c|c|c|}
\hline \multirow[t]{2}{*}{ Experiment No. } & \multicolumn{2}{|c|}{$\begin{array}{c}\text { Control Group } \\
\text { (Conventional Method) }\end{array}$} & \multicolumn{2}{|c|}{$\begin{array}{c}\text { Experimental Group } \\
\text { (Used Microscale Experiments) }\end{array}$} & \multirow[t]{2}{*}{ t-Value } & \multirow{2}{*}{$\begin{array}{c}\text { Sigma } \\
\text { (p-Value) }\end{array}$} \\
\hline & Mean & Interpretation & & Interpretation & & \\
\hline 1 & 2.97 & S & 3.96 & VS & 3.25 & $0.00^{* *}$ \\
\hline 2 & 3.52 & VS & 4.33 & $\mathrm{O}$ & 1.94 & $0.07^{\mathrm{ns}}$ \\
\hline 3 & 3.28 & VS & 3.98 & VS & 2.69 & $0.01^{* *}$ \\
\hline 4 & 3.67 & VS & 4.24 & $\mathrm{O}$ & 1.67 & $0.11^{\mathrm{ns}}$ \\
\hline 5 & 3.45 & VS & 4.08 & VS & 3.96 & $0.00^{* *}$ \\
\hline 6 & 3.53 & VS & 4.10 & VS & 2.93 & $0.01^{* *}$ \\
\hline 7 & 3.67 & VS & 4.07 & VS & 2.46 & $0.02^{*}$ \\
\hline 8 & 3.61 & VS & 3.94 & VS & 2.01 & $0.06^{\mathrm{ns}}$ \\
\hline 9 & 3.31 & S & 3.31 & VS & 1.94 & $0.06^{\mathrm{ns}}$ \\
\hline 10 & 3.40 & S & 4.01 & VS & 1.88 & $0.07^{\mathrm{ns}}$ \\
\hline 11 & 3.39 & S & 4.39 & $\mathrm{O}$ & 5.57 & $0.00^{* *}$ \\
\hline 12 & 3.25 & S & 4.27 & $\mathrm{O}$ & 4.88 & $0.00^{* *}$ \\
\hline
\end{tabular}

$4.21-5.00$ = Outstanding (O), $3.41-4.20$ = Very Satisfactory (VS), $2.61-3.40$ = Satisfactory (S), $1.81-2.60=$ Fair $(\mathrm{F}), 1.0-1.60=$ Poor $(\mathrm{P})$.

When the performance of the students along the psychomotor domain was compared, the p-values of the in experiments 2, 4, 8 and 9, is greater than 0.05 which implies that the mean score obtained by the students in these experiments are not significantly different indicating that the said experiments provided an equal degree of psychomotor development. Whereas, in experiment 7 , the p-value for the computed $t$ is less than 0.05 indicating a slight difference in the performance of the two groups of students. In experiments $1,3,5,6,11$, and 12, the $\mathrm{p}$-value for the computed $t$ are less than 0.01 signifying that the difference in the performance of the students are highly with the microscale groups having a better performance. This suggests that microscale experiments can develop students' psychomotor skills.

The introduction of microscale experiments in Chemistry is a positive reinforcement used to enhance the learning process and just like the findings in the study conducted by Orbeso [17] and Martinez [18] on computer aided instruction in teaching Chemistry which proved that using positive and innovative reinforcements can im- 
prove the performance of the students. The microscale experiments, as a reinforcement can contribute to the students' learning outcomes along the cognitive, psychomotor and affective domains. The results suggest that using the microscale experiments is an effective teaching innovation in delivering instruction to Chemistry. The effect is holistic in the sense that all the three aspects of learning domains are fully developed.

What is good with this study, is that the findings on researches on microscale chemistry has been proven to be true in the Philippines and the applicability of microscale experiments in the Philippine Educational System is highly possible. A cost analysis of the designed microscale experiments may be conducted to determine the amount of materials saved in this experiment.

Students' Learning Experiences in Performing the Microscale Experiments. The learning skills and experiences of the students were identified to assess the functionality and the suitability of the designed microscale experiments the attainment of the desired learning outcomes of the students.

Among the learning skills acquired by the students in the cognitive domain are the identifying and classifying substances, making predictions, calculating, observing, acquiring more knowledge, developing new ideas, making reflective thinking, understanding concepts and the like. These skills denote the different levels of cognition which started from knowledge, comprehension, application, analysis, to evaluation. Based on the students shared experiences, the microscale experiments were able to develop the desired learning outcomes along the cognitive side.

On the affective side, the students find the microscale experiments in chemistry interesting, very challenging, very exciting, motivating and enjoying. They also find the experiments as an avenue for developing the students' ability to work as a team, ability and to work responsibly and with confidence and cooperation. Most importantly, they find their experiences in microscale experiments very applicable to daily life activities. Students learned to follow instructions clearly and prepare the needed materials for the experiments. Based on the 6 levels of affective domains, the students have acquired the desired learning skills such as valuing, receiving and responding to phenomena, giving prompt actions to situations and internalizing new leanings into the system. The designed microscale experiments were able to develop positive learning values and behaviors which are manifestations of their affective skills development.

The learning outcomes of the students on the psychomotor side, the students were able to display lower level psychomotor skills checking of availability and correctness of materials (perception) measuring and following instruction and constructing molecular models (set), separating mixtures, measuring rates of chemical reaction, generating and collecting gases (guided response). Higher level psychomotor skills developed among students are assembling experimental set ups (Mechanism) and assembling and dismantling complex experimental set up (Complex Overt Responses).

The data suggest that the designed microscale experiments were able to develop relevant learning skills in the cognitive, affective and psychomotor aspect. This proves the functionality and suitability of the experiments in developing the students learning skills. Its purpose of developing the students' learning outcomes was met and using the microscale experiments in Chemistry is highly recommended.

One reason why students who used the microscale experiments is that everyone is given the opportunity to perform the experiments as an individual and as a small group. Hands on activities or direct learning experiences are effective learning process that could trigger the students to discover new things and learn from it. Downscaled experiments in chemistry did not just motivate the students to explore on new knowledge but triggered their curiosity and developed their critical thinking abilities. Students tend to search for an answer to that curiosity by performing more and more experiments at a microscale level in a minimal cost and in an environment friendly setting.

\section{Conclusions}

1) The designed microscale experiments were effective in developing the learning outcomes of the students in the three domains of learning: cognitive, affective, and psychomotor.

2) The experiments were able to improve the learning competencies of the students as manifested by their very satisfactory to outstanding performance in the formative tests given every after the conduct of each experiments in the three learning domains.

3) Students who used the microscale experiments in Chemistry have better learning outcomes than those who did not use the microscale experiments. 
4) The learning experiences of the students in performing microscale experiments facilitated the development of the students' learning outcomes in the different levels of cognition, affective and psychomotor domains and proved the functionality and suitability of the experiments in meeting the desired learning outcomes of the students.

\section{Recommendations}

The microscale experiments in Chemistry is a curricular innovation that can be used as one of the teaching strategies in providing the students with worthwhile learning experiences and which can lead to the development of their learning capabilities in the cognitive, affective and psychomotor domain. The approach provides the students an opportunity to discover new concepts at minimum cost and wastage of materials and administrators in the field of education may consider this as an option to use microscale experiments in their respective institutions. There's also a need to conduct more studies on the microscale experiments in both the secondary and tertiary level and observe the effect on how students would handle apparatus on the microscale level. There's also a need to study on the impact of microscale experiments to industry particularly those who specialize in Chemistry. More instructional materials and apparatus on the microscale level may be developed and observe how it will affect the students' learning competencies. A cost analysis of the microscale experiments may be conducted to determine its cost effectiveness and the degree of savings that will be incurred in performing microscale experiments.

\section{References}

[1] The National Microscale Chemistry Center (2002) http://www.microscale.org/

[2] University of Michigan (1997-1998) Microscale Chemistry in Undergraduate Teaching Laboratories. http://www.p2000.umich.edu/Chemical_Waste/Cw7.Htm

[3] Minnesota Technical Assistance Program (2009) Bemidji State University Reduces Chemistry Lab Waste by Almost 35\%. Regents of the University of Minnesota. http://www.mntap.umn.edu/labs/Resources/BSU.htm

[4] Boongaling and Hernandez (2009) Studies on Downscaling the Synthesis of 2,4-Dinitrophenylhydrazine from 1Chloro-2,4-Dinitrobenzene and Hydrazine. Souvenir Program and Book of Abstracts, Asia Pacific Conference on Chemistry Education and 24th Philippine Chemistry Congress, Tagbilaran, 16-19 April 2009, 56.

[5] Binas, et al. (2009) Low Cost Colometric Determination of Protein by Flow inspection Analysisicroscale Digital Polarimeter. Souvenir Program and Book of Abstracts, Asia Pacific Conference on Chemistry Education and 24th Philippine Chemistry Congress, Tagbilaran, 16-19 April 2009.

[6] Albano, D.R. and Sevilla III, F. (2009) Low Cost Electronic Thermometer for Microsclae Thermometry Experiments. Souvenir Program and Book of Abstracts, Asia Pacific Conference on Chemistry Education and 24th Philippine Chemistry Congress, Tagbilaran, 16-19 April 2009, 54.

[7] Cabral, C.L., Reyes, A.C., Solivas, J.L. and Hernandez, H.P. (2009) Validation of Downscaled Analyses of Acid and Ester Values of Essential Oils. Souvenir Program and Book of Abstracts, Asia Pacific Conference on Chemistry Education and 24th Philippine Chemistry Congress, Tagbilaran, 16-19 April 2009.

[8] (2005) YCCD Academic Senate March 10, 2005 Student Learning Outcomes. www.imt.liu.se/edu/Bologna/LO/slo.pdf

[9] Adam, S. (2004) Using Learning Outcomes: A Consideration of the Nature, Role, Application and Implications for European Education of Employing "Learning Outcomes” at the Local, National and International Levels. United Kingdom Bologna Seminar, 1-2 July 2004, Heriot-Watt University (Edinburgh Conference Centre), Edinburgh. www.qualityresearchinternational.com/glossary/learningoutcomes.htm

[10] Lesch, S. (2012) Learning Outcomes, Learning Achieved by the End of a Course or Program Knowledge-Skills-Attitudes. George Brown College. http://liad.gbrownc.on.ca/programs/InsAdult/currlo.htm

[11] Gravoso, S., Pasa, A.E. and Labra, J. (2007) Design and Use of Instructional Materials for Student-Centered Learning: A Case in Learning Ecological Concepts. Asia-Pacific Education Researcher, 17, 109-120. http://dx.doi.org/10.3860/taper.v17i1.353

[12] Lemay, H.E. (2002) Chemistry Connections to Our Changing World. Mass. Prentice Hall, Inc., Needham.

[13] Slowinski, E., et al. (2005) Chemical Principles in the Laboratory. 8th Edition, Brookes Cole, USA.

[14] Beran, J.A. (2004) Laboratory Manual for the Principles in General Chemistry. 7th Edition, John Wiley and Sons, Inc., New Jersey.

[15] Silberberg, M.S. (2002) Purdue University Special Edition of General Chemistry. McGraw Hills Co., USA. 
[16] Rodriguez, M.S. and de Mesa, Ma.C. (2001) Fundamentals of Concepts of Chemistry II. Vol. 1, UPOU.

[17] Orbeso, R.A. (2002) Computer Assisted Instruction and Science Learning. Unpublished Master’s Thesis, Partido State University, Goa.

[18] Martinez, M. (2005) Computer Aided Instruction in Teaching Chemistry in the Secondary Schools. Unpublished Master's Thesis, Partido State University, Goa. 